\title{
Projeto Resgate: História e arquivística (1982-2014)
}

The Resgate Project: History and Archival Science (1982-2014)

Caio César Boschi *,

\section{Resumo}

A consulta, cada vez mais intensa, aos chamados documentos de arquivo exige dos historiadores conhecimentos, ainda que elementares, da arquivística e da arquivologia, sobretudo no que respeita ao tratamento técnico conferido aos acervos, no mínimo, para evitar equívocos interpretativos. Duas das noções básicas dessas áreas - o princípio da proveniência e o da organicidade - são aqui consideradas à luz da trajetória do Projeto Resgate "Barão do Rio Branco", especialmente nas lides de organização, rearmazenamento e reprodução microfílmica e digital dos resultados alcançados relativamente aos conjuntos documentais custodiados no Arquivo Histórico Ultramarino (AHU), em Lisboa. Essas anotações pretendem também subsidiar a discussão em torno de futuras ações do referido projeto.

Palavras-chave: Arquivística; Projeto Resgate; acessibilidade; proveniência; organicidade.

\begin{abstract}
The increasingly intense consultation of archive documents demands historians to have knowledge, even if elementary, of archival process and archival science, especially concerning the technical treatment of documental collections, most of all to avoid interpretative misunderstandings. Two of the basics of these areas - the provenance principle and the organicity principle - are considered here in the light of the Projeto Resgate "Barão do Rio Branco" trajectory, especially in the tasks of organizing, re-storing and microfilm and digital reproduction of its results concerning the group of documents under custody of the Arquivo Histórico Ultramarino, in Lisbon. From that point, these annotations also intend to subsidize discussions about future actions of that project.

Keywords: Archival Science; Resgate Project; accessibility; provenance; organicity.
\end{abstract}

\footnotetext{
* Pontifícia Universidade Católica de Minas Gerais (PUC Minas), Departamento de História. Belo Horizonte, MG, Brasil. caioboschi@hotmail.com <https://orcid.org/0000-0003-0665-2563>
} 
Todo livro de História digno deste nome deveria incluir um capitulo, ou, se quiserem, inserir nos pontos capitais do discurso, uma série de parágrafos que se intitularia mais ou menos: "como pude apurar o que vou dizer".

Marc Bloch

Por ocasião das discussões em torno do Projeto de Lei no 4699/2012, que regulamenta a profissão de historiador, a Associação Nacional de História (Anpuh), atendendo a que "a crescente valorização da memória e as novas temáticas da historiografia têm ampliado a participação dos historiadores em arquivos, centros de memória e centros de documentação", criou grupos de ação para definir o perfil dos historiadores atuantes em arquivos. Em documento amplamente divulgado, o grupo encarregado de discutir os vetores e os instrumentos de formação daqueles profissionais assim se manifestou:

considerando a atuação desses profissionais na avaliação, organização, definição das políticas de descrição e difusão de documentos de arquivo, a formação do historiador deve capacitá-lo para lidar com conjuntos documentais arquivísticos, garantindo a aquisição de determinadas competências e habilidades, tais como:

- compreensão das transformações da História e sua relação com a constituição de acervos;

- compreensão dos princípios e práticas da Arquivologia, bem como do processo histórico de concepção e consolidação dessa área de conhecimento;

- identificação das implicações provocadas pelas transformações tecnológicas sobre os princípios e as práticas da Arquivologia e da pesquisa histórica;

- conhecimento dos diferentes perfis das instituições arquivísticas e de seu funcionamento;

- reconhecimento das especificidades dos documentos de arquivo;

- compreensão das diferenças e semelhanças entre conjuntos documentais arquivísticos institucionais, pessoais e familiares;

- reconhecimento das origens dos conjuntos arquivísticos e das implicações deste fator na composição e organização dos acervos;

- desenvolvimento de pesquisas históricas relacionadas a diferentes etapas do processo de tratamento dos conjuntos documentais arquivísticos. 
Em paralelo, desde a década de 1990 observa-se a emergência de debates de estudiosos da História em vários setores relativamente aos reflexos metodológicos e epistemológicos resultantes da compilação de grandes massas documentais que vem sendo proporcionada pelo emprego das novas tecnologias na identificação, na organização e, mormente, na reprodução das fontes históricas. Isto porque, dentre outras implicações, os estudiosos apuram que o contato com os documentos de arquivos não se esgota na coleta/obtenção e na anotação de informações. Sem esquecer que a operação da leitura/consulta oferece-nos, em simultâneo, organizar "de forma cada vez mais elaborada novas maneiras de pensar a História” (Farge, 2009, p.29).

Assim, em tempos recentes, a operação historiográfica

viu o seu próprio material de trabalho começar a questionar-se em si próprio e a recusar o estatuto passivo de matéria bruta a ser trabalhada pelo historiador ... Nas últimas duas décadas, grupos de historiadores particularmente atentos à questão da escrita e da documentalidade empreenderam uma reflexão sobre um regresso às fontes que, embora rejeitando qualquer neopositivismo simplista, incluísse questionamentos sobre o documento muito para além dos conteúdos, indo até aos contextos de registro, conservação e organização da informação. Incorporar nas problematizações historiográficas as sucessivas transformações da informação - incluindo a que desapareceu - é hoje em dia, de forma cada vez mais disseminada, um requisito fundamental de uma análise histórica complexa. (Rosa, 2012, p.22)

Nesse contexto, os apontamentos que se seguem têm duplo propósito. $\mathrm{O}$ primeiro, o de reunir informações esparsas sobre um empreendimento que encerra por objetivo realizar a identificação, o tratamento e a disponibilização de alentados volumes documentais, cujos resultados até agora produzidos vêm alterando substancialmente os estudos históricos concernentes à América portuguesa. O segundo, o de analisar, ainda que sucintamente, algumas ocorrências dessa operação nos moldes dos intuitos estabelecidos no repto lançado pelo supracitado documento da Anpuh.

\section{Projeto Resgate: antecedentes}

Desde a criação do Instituto Histórico e Geográfico Brasileiro (IHGB), foram desenvolvidos esforços visando a que se pudesse ter acesso, no Brasil, à 
documentação a nós respeitante, mas depositada em instituições estrangeiras. ${ }^{2}$ Porém, somente no final do século passado é que, dado o progresso e a disseminação da reprodução microfílmica de documentos, reavivaram-se as propostas dos pioneiros de 1838 e de seus abnegados seguidores. ${ }^{3}$

Como aconteceu esse percurso? A referência inicial - e simbólica - é o Projeto de Microfilmagem da Documentação relativa ao Brasil no Exterior, veiculado em meados de 1982 e formalmente apresentado em reunião havida no Palácio Itamarati, no Rio de Janeiro, em 13 de setembro daquele ano, sob os auspícios da Fundação Nacional Pró-Memória e da Fundação Alexandre de Gusmão. A proposta espelhava-se na experiência adquirida pelo Plano Nacional de Microfilmagem de Periódicos Brasileiros e, por razões óbvias, Portugal foi o país escolhido para nele se começar o trabalho.

Em janeiro de 1992, a então Secretaria de Cultura do ex-Ministério da Educação e Cultura, por empenho de seu assessor especial, embaixador Wladimir Murtinho, retomou a proposta, que, no entanto, somente se concretizou 3 anos depois, quando,

inserido nas comemorações do V Centenário do Descobrimento do Brasil, o Ministério da Justiça brasileiro firmou, em 16 de agosto de 1995, com a Presidência do Conselho de Ministros da República Portuguesa um protocolo de colaboração visando a estimular a permuta de informações contidas nos acervos arquivísticos de interesse mútuo, sob a guarda de cada um dos países intervenientes. (Coluso, 2014)

Para preparar o desenvolvimento das atividades, criou-se em fevereiro de 1996 a Comissão Luso-Brasileira para a Salvaguarda e Divulgação do Patrimônio Documental (Coluso), ${ }^{4}$ cujas primeiras ações pautaram-se por acordo celebrado, 4 meses antes, entre o Instituto de Investigação Científica e Tropical, de Portugal, e o Ministério da Cultura, do Brasil, para a microfilmagem da documentação sobre o Brasil-Colônia existente no Arquivo Histórico Ultramarino (AHU), em virtude de ser esta a instituição que abriga o maior volume de documentos sobre as antigas possessões coloniais portuguesas.

Por já ter sido organizado e referenciado, o acervo relativo à Capitania de Minas Gerais foi disponibilizado para os primeiros cuidados de microfilmagem. ${ }^{5}$ Em simultâneo, sob a tutela da Coluso, iniciaram-se as atividades do Projeto Resgate "Barão do Rio Branco", 6 que envolveu mais de cem pessoas, vinculadas fundamentalmente a cerca de cinquenta instituições brasileiras, nas 
tarefas de organização, leituras paleográfica e diplomática, datação e sumariação/verbetação dos documentos manuscritos existentes em mais de 2 mil caixas metálicas da chamada Série Brasil do AHU. ${ }^{7}$ Processo que, ao longo de 5 anos, foi sendo cumprido com incontáveis percalços, mas, sobretudo, com a obtenção de consideráveis resultados que vão expostos na Tabela 1.

Tabela 1 - Arquivo Histórico Ultramarino

Séries Documentais Relativas ao Brasil

\begin{tabular}{|c|c|c|}
\hline Séries / Capitanias & Catálogos & Verbetes \\
\hline ALAGOAS (1680-1826) & 01 & 532 \\
\hline BAHIA & & \\
\hline Avulsos (1604-1828) & 03 & 19.610 \\
\hline Castro e Almeida (1613-1807) & 05 & 30.374 \\
\hline Luísa da Fonseca (1599-1700) & 01 & 4.384 \\
\hline CEARÁ (1618-1832) & 01 & 1.436 \\
\hline CÓDICES I (1548-1821) e II (1671-1833) & 01 & 759 \\
\hline $\begin{array}{l}\text { COLÔNIA DO SACRAMENTO } \\
\text { E DO RIO DA PRATA (1585-1822) }\end{array}$ & 01 & 1.224 \\
\hline CONSELHO ULTRAMARINO & & \\
\hline Diversos & 01 & 7.728 \\
\hline ESPÍRITO SANTO (1585-1822) & 01 & 549 \\
\hline GOIÁS (1585-1822) & 01 & 2.950 \\
\hline MARANHÃO (1614-1833) & 01 & 13.118 \\
\hline MATO GROSSO (1720-1827) & 01 & 2.221 \\
\hline MINAS GERAIS (1680-1832) & 03 & 13.916 \\
\hline PARÁ (1616-1833) & 03 & 12.690 \\
\hline PARAÍBA (1593-1826) & 01 & 3.523 \\
\hline PERNAMBUCO (1590-1826) & 04 & 20.029 \\
\hline PIAUÍ (1684-1828) & 01 & 1.716 \\
\hline RIO DE JANEIRO & & \\
\hline Avulsos (1614-1830) & & 20.964 \\
\hline Castro e Almeida (1617-1757) & 03 & 20.485 \\
\hline RIO GRANDE DO NORTE (1623-1823) & 01 & 684 \\
\hline
\end{tabular}




\begin{tabular}{l|c|c}
\hline RIO GRANDE DO SUL (1732-1825) & 01 & 822 \\
\hline RIO NEGRO (Amazonas) (1723-1825) & 01 & 750 \\
\hline SANTA CATARINA (1717-1827) & 01 & 619 \\
\hline SÃO PAULO & 03 & 1.383 \\
Avulsos (1644-1830) & 15 & 5.113 \\
Mendes Gouveia (1618-1823) & 01 & 2.020 \\
\hline SECRETARIA DO CONSELHO ULTRAMARINO & 01 & 641 \\
Avulsos (1642-1833 & & 7.728 \\
\hline SERGIPE (1619-1822) & 01 & \\
\hline ARQUIVO HISTÓRICO ULTRAMARINO & & \\
Séries - Avulsos & 64 & 198.475 \\
\hline ARQUIVO HISTÓRICO ULTRAMARINO - & & \\
CARTOGRAFIA/ICONOGRAFIA & & \\
Diversos & & \\
\hline Total: & & \\
\hline
\end{tabular}

Fonte: Coluso, 2014, p.89 (adaptação).

Na primeira hora, esses resultados se materializaram também e correspondentemente na reprodução digitalizada em mais de $300 \mathrm{CD}$-ROMs, cujas cópias foram distribuídas pelo Ministério da Cultura do Brasil, no princípio deste século, preferencialmente para arquivos estaduais, para instituições de pesquisa histórica e para bibliotecas especializadas, particularmente aquelas vinculadas a cursos de graduação e pós-graduação em História.

Já agora, no entanto, para satisfação geral, todos os trabalhos - catálogos e reprodução documental - estão disponíveis on-line, graças a louvável iniciativa da Biblioteca Nacional do Brasil (cf. https://bndigital.bn.gov.br/dossies/ projeto-resgate-barao-do-rio-branco/).

A simples consulta à produção historiográfica nos últimos anos evidencia, entretanto, que apenas parte dos feitos do Projeto Resgate vem sendo apropriada pelos estudiosos. Observando-se as referências às fontes manuscritas do AHU relativas ao Brasil aludidas em textos acadêmicos e em outras publicações, verifica-se que elas, quase que exclusivamente, pertencem à documentação não encadernada, aos popularmente denominados "avulsos" das ditas "capitanias".

Raras são as citações de dados contidos em outros fundos, igualmente inventariados, microfilmados e digitalizados no âmbito do projeto que tem 
lastro e consistência na série em pauta. Quando não a substitui (no caso, por exemplo, pelos registros consignados em códices) ou a complementa, por vezes, indispensavelmente (caso das espécies cartográficas). Assim, não obstante a disponibilização de instrumentos de busca e da retenção imagética das espécies, quase não se vê menção ou transcrição de notações dos livros de registros, dos códices ${ }^{8}$ ou mesmo da documentação "avulsa" da Secretaria do Conselho Ultramarino ${ }^{9}$ ou do substancioso acervo cartográfico e iconográfico do AHU, ${ }^{10}$ bem como de documentos "Diversos" (sic) que integram séries de pequena monta, mas não menos importantes para a história brasileira. ${ }^{11}$

Não esquecendo, também, da série Reino, reunião de aproximadamente 30 mil documentos manuscritos avulsos, datados entre 1445 e 1831, dispostos em 476 caixas metálicas, ora em processo de organização preliminar, com descrição documental já realizada, e disponível em instrumento de pesquisa próprio. (Cf. http://actd.iict.pt/eserv/actd:CUc076/CU-Reino.pdf). ${ }^{12}$

Em bom rigor, o rol das fontes históricas em pauta e a abordagem do objeto-tema deste texto, no tocante ao AHU e ao Projeto Resgate, não podem fazer abstração dos acervos documentais de outros territórios do império colonial português que interagiram com a América portuguesa. Pelo contrário. É redundante afirmar-se que a boa compreensão da nossa história, pelo menos até o século XIX, está umbilicalmente associada àqueles espaços e ao estudo do processo de colonização da Época Moderna, do conhecimento das estruturas e dos mecanismos que movem tal processo, bem como das reações dos povos que até bem recentemente estiveram sob o jugo português.

Assim e limitando as referências às possessões africanas, apontem-se instrumentos de pesquisa que informam o conteúdo dos fundos e séries sobre a África portuguesa custodiados no mencionado arquivo.

1. Série Angola, totalizando 181 caixas metálicas, com 16.315 documentos, que abrangem o período de 1602 a 1833. Há catálogo parcial, com descrição de 4.676 documentos compreendidos até 1765 . Vale dizer, a identificação do conteúdo das primeiras 49 caixas (cf. http://actd.iict.pt/eserv/actd:CUc001/ CU-Angola-Parcial.pdf)..$^{13}$

2. Série Cabo Verde, 112 caixas, com 8.024 documentos, entre 1614 e 1833. Está disponível em catálogo parcial com descrição de 2.183 documentos que se estendem até 1767 , ou seja, a identificação dos componentes das primeiras 30 caixas (cf. http://actd.iict.pt/eserv/actd:CUc024/CU-CaboVerde-Parcial.pdf).

3. Série Guiné, abarcando 26 caixas, com 2.086 documentos, datados de 1602 a 1833. O catálogo parcial lista 1.025 documentos com data final em 1786. Foram identificados os manuscritos depositados nas primeiras 13 caixas (cf. http://actd.iict.pt/eserv/actd:CUc049/CU-Guine-Parcial.pdf). 
4. Série São Tomé e Príncipe, 60 caixas, com 4.135 documentos, balizados cronologicamente entre 1538 e 1834. Estão catalogados 954 documentos compreendidos até 1753 , isto é, o conteúdo das primeiras 8 caixas (cf. http://actd. iict.pt/eserv/actd:CUc070/CU-SaoTome-Parcial.pdf).

5. Série Moçambique, disposta em 267 caixas, com 25.325 documentos, do período de 1605 a 1893. Há catálogo parcial, com descrição de 13.317 documentos compreendidos até 1834 . Vale dizer, a identificação do constitutivo de 63 caixas não sequenciadas cronologicamente (cf. http://actd.iict.pt/eserv/ actd:CUc064/CU-Mocambique-Parcial.pdf).

A essa documentação "avulsa” acrescente-se a de natureza cartográfica manuscrita, ${ }^{14}$ conforme se constata para o conjunto do continente em: http:// ahu.dglab.gov.pt/wp-content/uploads/sites/24/2016/09/CatalogoPT-AHUCARTM.pdf.

Reafirme-se, então, a necessidade de os pesquisadores desvencilharem-se definitivamente de interpretações bipolarizadas, isto é, restritas às relações Portugal-Brasil, e de cultivarem visão mais completa do que seja a globalidade subjacente e compreendida pelo complexo colonial português. Ou seja, e aí outra obviedade: à medida que os fundos documentais das demais ex-colônias forem sendo organizados e disponibilizados, estaremos nos aproximando de compreensão mais sólida e estrutural dos nossos respectivos e imbricados passados históricos. Estaremos conferindo maior consistência e densidade à noção de império ultramarino português, pelo (re)conhecimento de nossas afinidades, mas também e principalmente, pela identificação de nossas diferenças. Por tudo isso, é auspicioso verificar que, nos últimos tempos e ainda sem ser unanimidade no meio acadêmico-científico, os historiadores brasileiros têm se aberto à análise e à intelecção do sentido do Império português para além do território e da realidade histórica metropolitana.

A referir, ademais, que as atividades desenvolvidas pelas instituições integrantes das duas seções da Coluso estendem-se para áreas específicas. Isto é, a feitura da identificação, organização, reprodução e permuta de conjuntos documentais de propriedade dos ministérios dos exércitos, das marinhas e das relações exteriores dos dois países, de que são exemplos, respectivamente, $\mathrm{o}$ projeto "Tratamento das coleções referentes aos códices militares do Império português / Corte (1808-1823)", o acervo "Memorial naval brasileiro na Independência do Brasil (1796-1895)" e o projeto “Organização e descrição de documentos dos períodos colonial e imperial brasileiro: as comissões mistas e os tribunais mistos", este último sob a responsabilidade do Arquivo Histórico do Itamaraty (Coluso, 2014, p.105, 97 e 106). 
Mencione-se também que, do lado português, a bilateralidade prevista no Protocolo de Colaboração configurou-se no chamado Projeto Reencontro. Nesse sentido, desde 1996, a seção portuguesa da Coluso, ao identificar volumes documentais de seu interesse existentes em instituições arquivísticas de nosso país, solicita à congênere brasileira as devidas reproduções microfílmicas e/ou digitalizadas. Desse modo, em reciprocidade, foram providenciados, entregues e estão depositados no Arquivo Nacional da Torre do Tombo, em Lisboa, mais de 600 rolos de microfilmes contendo cópias de fundos e séries documentais do Arquivo Nacional do Brasil (exemplos: Chancelaria Mor do Estado/Reino do Brasil, Conselho da Fazenda, Mesa do Desembargo do Paço do Estado do Brasil, Secretaria das Mercês do Brasil e Negócios de Portugal), da Divisão de Manuscritos da Biblioteca Nacional do Rio de Janeiro (exemplos: Coleções Portugal, Morgado de Mateus, Linhares e Casa dos Contos), do Arquivo Público Mineiro (exemplos: Seção Colonial/Secretaria do Governo), do Arquivo Histórico do Estado da Bahia (exemplos: Ordens régias, entre 1648 e 1800, e Matrículas dos engenhos e de sesmarias). ${ }^{15}$

Outra lembrança, fazendo-se remissão ao enunciado no começo deste tópico, é que os desígnios do Projeto Resgate não se esgotam em Portugal. Há realizações importantes em outros países detentores de documentação atinente à história brasileira. Na Tabela 2 estão estampadas algumas realizações dessa modalidade de trabalhos.

Tabela 2 - Guias de Fontes do Projeto Resgate "Barão do Rio Branco" Países, cidades e instituições culturais pesquisadas

\begin{tabular}{l|c|c}
\hline \multicolumn{1}{c|}{ Países/Guias } & Cidades & Instituições \\
\hline Áustria & 6 & 18 \\
\hline Bélgica & 6 & 14 \\
\hline Espanha & 14 & 38 \\
\hline Estados Unidos & 17 & 40 \\
\hline França & 21 & 36 \\
\hline Holanda & 7 & 7 \\
\hline Irlanda e Grã-Bretanha & 39 & 69 \\
\hline Itália & 18 & 41 \\
\hline \multicolumn{1}{c|}{ Total: } & 128 & 263 \\
\hline
\end{tabular}

Fonte: Coluso, 2014, p.87. 
Condição atual dos guias:

Áustria: Preparado, mas ainda não publicado.

Bélgica: ULRICH, Sônia Maria X. de A. Guia de fontes manuscritas para a História do Brasil na Bélgica (1500-1922). Brasília: Ministério da Cultura / Diretoria de Relações Exteriores, 2011. 235p.

Espanha: MARTINEZ, Elda E. González. Guia de fuentes manuscritas para la Historia del Brasil conservadas en España (Guia de fontes manuscritas para a História do Brasil conservadas em Espanha). Madrid: Fundación Tavera, 2002. 702p. Disponível em: http://objdigital.bn.br/objdigital2/acervo_digital/div_ manuscritos/mss1054736/mss1054736.pdf; acesso em: 22 jan. 2018.

Estados Unidos: ALMEIDA, Paulo Roberto de; BARBOSA, Rubens Antônio; FINS, Francisco Rogido (Org.) Guia dos arquivos americanos sobre o Brasil: coleções documentais sobre o Brasil nos Estados Unidos. Brasília: Funag, 2010. 244p.

França: MACHADO, Marco Antônio G. (Org.) Guia de fontes para a história franco-brasileira: Brasil Colônia, Vice-Reino e Reino Unido. Recife: L. Dantas Silva, 2002. 303p.

Holanda: GALINDO, Marcos; HULSMAN, Lodewijk (Org.) Guia de fontes para a História do Brasil-Holandês: acervos de manuscritos em arquivos holandeses. Brasília: MinC/Projeto Resgate; Recife: Fundação Joaquim Nabuco/ Massangana, 2001. 376p.; WIESENBRON, Marianne L. (Ed.) O Brasil em arquivos neerlandeses (1624-1654): introdução aos Países Baixos do século dezessete e às coleções em arquivos e bibliotecas neerlandesas. Leiden: Research School CNWS, 2004. 182p. ${ }^{16}$

Irlanda e Grã-Bretanha: MARSHALL, Oliver. Brazil in British and Irish Archives. 2.ed. Oxford: University of Oxford/Center for Brazilian Studies, 2008. 288p.

Itália: AVELLA, Aniello A. (Sup.) Guia de fontes para a História do Brasil Colonial conservadas nos institutos e arquivos italianos. Rio de Janeiro: Eduerj, 2013. $576 \mathrm{p} .{ }^{17}$

Isso posto, torna-se fundamental que, a partir desses instrumentos, seja identificada e tecnicamente tratada a documentação neles arrolada, a fim de que, baseando-se em sua catalogação, se processe à microfilmagem e digitalização, bem como à democratização dos efeitos.

De qualquer das maneiras, nessa vertente já se conhecem duas exitosas experiências de identificação e inventariação, a saber: no que tange aos acervos 
espanhóis: CABRIA, Juan Vicente Bachiller. Cartografía manuscrita de Brasil en las colecciones españolas (1500-1822). / Cartografia manuscrita do Brasil nas coleções espanholas (1500-1822). Salamanca: Universidad de Salamanca/ Centro de Estudios Brasileños/Globalia, 2008. 294p. Ao lado do catálogo organizado por Maria Dulce Faria (cf. nota 10), esse instrumento de busca instiga a implementação de uma área de pesquisa que tem se desenvolvido, com sucesso, no Brasil, nos últimos anos. Basta citar as comunicações apresentadas e debatidas nos Simpósios Brasileiros de Cartografia Histórica. O primeiro teve lugar em Paraty, no estado do Rio de Janeiro, em maio de 2011. O segundo, na cidade de Tiradentes (MG), em maio de 2014. O terceiro, em Belo Horizonte (MG), em outubro de 2016. Anote-se, além desses, o VII Simpósio Luso-brasileiro de Cartografia Histórica, sediado na cidade do Rio de Janeiro, em novembro de 2017. Sem esquecer que, em julho de 2017, não por acaso, e pela primeira vez sediada no Hemisfério Sul, aconteceu em Belo Horizonte a 27th International Conference on the History of Cartography.

\section{A Arquivística e o / no Projeto Resgate}

A maior participação dos historiadores na vida dos arquivos, conforme proclama o documento da Anpuh, pressupõe a disposição desses profissionais na observância e no domínio de conhecimentos específicos. Para o exercício aqui proposto, são destacados três dos "vetores" daquele texto. Com o emprego de conceituação pertinente, eles são analisados a seguir quanto à sua presença nas ações levadas a efeito no principal foco de lavor do Projeto Resgate: o acervo documental custodiado no Arquivo Histórico Ultramarino (AHU), em Lisboa.

As competências e habilidades escolhidas foram:

- o conhecimento dos diferentes perfis das instituições arquivísticas e de seu funcionamento; reconhecimento das especificidades dos documentos de arquivo;

- o reconhecimento das origens dos conjuntos arquivísticos e das implicações deste fator na composição e organização dos acervos; e

- o desenvolvimento de pesquisas históricas relacionadas a diferentes etapas do processo de tratamento dos conjuntos documentais arquivísticos.

Pode-se inferir dos enunciados que, grosso modo, eles são atinentes a dois postulados básicos da Arquivística: o princípio da proveniência e o da 
organicidade. Proveniência é uma premissa segundo a qual “o arquivo produzido por uma entidade coletiva, pessoa ou família não deve ser misturado aos de outras entidades produtoras. Também chamado princípio do respeito aos fundos" (Dicionário..., 2005, p.136). Já a organicidade é a "relação natural entre documentos de um arquivo em decorrência das atividades da entidade produtora" (Dicionário..., 2005, p.127). ${ }^{18}$

Às observações, então. Criado em 1931, o AHU “incorporou nos seus depósitos os documentos mais antigos que constituíam a Seção Ultramarina da Biblioteca Nacional [de Portugal] e os fundos documentais do Ministério das Colônias, depois [Ministério] do Ultramar" (Martinheira, 2001, p.24). A documentação, na altura, foi organizada em três fundos principais: o Conselho Ultramarino (século XVI a 1833), a Secretaria de Estado da Marinha e do Ultramar (1834 a 1910), e o Ministério do Ultramar (1911 a 1975).

Como se verifica pelas balizas cronológicas convencionadas para cada um dos fundos, apenas o primeiro é objeto de interesse para estas anotações. $\mathrm{Na}$ realidade, a despeito da nomenclatura adotada, o fundo de arquivo do Conselho Ultramarino não se compõe apenas da documentação provinda do órgão homônimo. A ela se juntou o acervo originário da Secretaria de Estado dos Negócios da Marinha e dos Domínios Ultramarinos, mais comumente designada por Secretaria de Estado da Marinha e do Ultramar.

Ainda tendo em conta as referidas balizas, enfatize-se que, não obstante a denominação do segundo fundo, os documentos emanados ou recebidos pela Secretaria relativos à América portuguesa integram o primeiro, isto é, o do Conselho Ultramarino. Vale dizer: no que tange ao Brasil Colonial, o acervo de "manuscritos avulsos", de livros, códices, da iconografia e da cartografia do Conselho Ultramarino, organismo criado em 1642, funde-se e confunde-se com o da Secretaria de Estado da Marinha e do Ultramar, instituída em $1736 !^{19}$ De todo modo, é "visível na documentação avulsa que a correspondência recebida do ultramar é, até a primeira metade do século XVIII, constituída por cartas e requerimentos dirigidos ao rei, e depois por ofícios ao secretário de Estado. São, pois, dois momentos distintos em que o expediente corre primeiro pelo Conselho Ultramarino, e depois pela Secretaria de Estado" (Martinheira, 2001, p.27).

Com efeito, em 1833, em virtude da extinção do Conselho Ultramarino, o acervo documental a ele atinente foi incorporado ao arquivo da Secretaria. Ou seja, durante o século XIX, a documentação dos dois órgãos literalmente se misturou, pelo menos em parte. Em 1899, o conjunto documental foi 
integrado à Biblioteca Nacional de Portugal, "sendo constituído à época por 1.857 maços de papéis avulsos, bem como [por] um número significativo de códices ... Em 1897, houve nova incorporação de documentação proveniente do Arquivo da Direção Geral da Marinha, do Comando Geral da Armada e dos arquivos de vários navios de guerra. Por decreto de 24 de dezembro de 1901, foi criada na Biblioteca Nacional a coleção 'Arquivo da Marinha e Ultramar” (Gregório, 2017, p.70), núcleo formador do Arquivo Histórico Colonial, denominação primitiva do AHU. ${ }^{20}$

Registre-se, além disso, que, sendo órgão central, o Conselho Ultramarino ainda hoje não dispõe de estudos analíticos compatíveis com a sua importância e com a sua condição planejadora e decisória da política do império marítimo português. O texto mais próximo sobre a trajetória do Conselho é o estudo publicado em 1943 por Marcelo Caetano, ${ }^{21}$ o qual, como bem ressalva Myrup, "dedica apenas 15 páginas [p.23-38] para a história do órgão propriamente dita", cabendo observar, além disso, que todos os trabalhos posteriores se reportam a ele (Myrup, 2009, p.266). ${ }^{22}$

Quanto à Secretaria de Estado da Marinha e do Ultramar, a produção historiográfica é ainda mais escassa. Praticamente nenhum estudo específico lhe é dedicado; tão somente referências laterais ou paralelas às de órgãos criados na oportunidade. ${ }^{23}$

Se assim é, e reportando-se aos parâmetros normativos da Arquivística, como identificar e compreender as condições e as motivações da produção documental do acervo do AHU? Como detectar o processo de produção e fluxo dos documentos ali depositados? Como discernir entre os dois órgãos aquele que foi o produtor/recebedor/acumulador da documentação sobre a América portuguesa, em particular das espécies não encadernadas, razão principal do labor do Projeto Resgate? Acrescente-se a essa vicissitude o fato de, ainda que tendo clara a contingência, o AHU ter optado por não proceder à "reposição da originalidade e organicidade destes fundos", mantendo reunida a documentação antiga, até 1833, e designando-a fundo de arquivo do Conselho Ultramarino (Martinheira, 2001, p.27).

No AHU, a organização da documentação avulsa pautou-se basicamente pela ordenação cronológica das peças, secundada pelo viés cronológico, dando sequência, pois, ao norte organizativo anteriormente adotado na Biblioteca Nacional. A opção em causa gera problemas, embora sanáveis. Por exemplo: a Capitania de Alagoas surgiu em setembro de 1817, por desmembramento da 
Capitania de Pernambuco. Na subsérie homônima do AHU, no entanto, o conjunto documental abrange o período de 1680 a 1826.

Para mais, sem desconsiderar que é impossível apreender a dinâmica histórica de certas áreas da Colônia, há que interpenetrar e integrar reciprocamente a documentação a elas referentes. Por exemplo, não se pode bem compreender e analisar a realidade histórica colonial do Pará sem a consulta, no mínimo, à documentação respeitante ao Rio Negro e ao Maranhão; não há como bem estudar o Continente de São Pedro sem compulsar as fontes sobre a Colônia do Sacramento e do Rio da Prata, as quais, por sua vez, a aplicar o critério da territorialidade, não deveriam integrar a Série Brasil.

Um último apontamento. A despeito de sua intenção original, o AHU não preserva a totalidade do conjunto dos documentos que o inspiraram e o nomeiam. Na Divisão dos Reservados da Biblioteca Nacional de Portugal podem ser encontradas peças encadernadas e "avulsos" que não foram transferidos para o antigo Palácio dos Condes da Ega, sede do AHU. Em outras palavras, a massa documental que pertenceu ao Ministério das Colônias, à qual então se aduziu o Arquivo da Marinha e Ultramar e a Seção Ultramarina da Biblioteca Nacional, tem parte depositada nesta última instituição. A destacar, também, que, em pelo menos outras duas entidades lisboetas, na Torre do Tombo ${ }^{24}$ e no Arquivo Histórico da Marinha, ${ }^{25}$ há documentação concernente ao Conselho Ultramarino.

E quanto à organicidade? Antes de mais, considere-se a indispensável percepção do histórico e das condições de incorporação, bem como dos critérios norteadores das formas de organização da documentação. Significa afirmar que o historiador deve exercer papel importante na tarefa de identificar a lógica interna e de (re)estabelecer as relações intrínsecas e internas existentes na documentação que consulta, em especial naquela que agrupa e à qual atribui harmonia e homogeneidade. Recuperar a informação por intermédio da percepção das relações de organicidade e, assim, aproximar-se, ao máximo, do conhecimento das competências, funções, ações e atuações dos órgãos administrativos do período considerado. Em suma, captar "a coerência lógica e orgânica no contexto de produção, o vínculo aos outros documentos do mesmo conjunto" (Bellotto, 2014, p.332).

Repita-se: há necessidade do conhecimento das estruturas político-administrativas e burocráticas, bem como da trajetória das instituições coloniais para a melhor compreensão das ações por elas desenvolvidas e dos fenômenos históricos a que elas estão vinculadas. Como ressalta Lurdes Rosa: 
o estudo do organismo produtor permite alcançar a natureza e a autoridade da informação; o estudo da forma como ele conserva os documentos permite verificar como se usa essa mesma informação, como se constrói e se é construído por ela. A organização a partir do produtor permite, além disso, partir do universo informacional total, e não do que resta; incorporar o conhecimento do que foi conservado realmente, permite perceber que qualquer conservação não é 'natural', nem 'total', mas sim social e seletiva. (Rosa, 2012, p.29)

Por ignorarmos, em grande medida, a estrutura e o funcionamento dos órgãos administrativos da e na Colônia e dos recorrentes Conselho Ultramarino e Secretaria de Estado da Marinha e do Ultramar, é fragmentado e limitado o entendimento que possuímos tanto da gênese como da tramitação dos documentos neles e entre eles produzidos. Problema que se acentua diante da reconhecida complexidade e das idiossincrasias do aparelho de Estado português da Época Moderna. Logo, torna-se primordial a superação desses obstáculos ou, quando menos, que nos esforcemos para atingi-la, dado que, insista-se, a Arquivística nos ensina que conhecer a gênese do documento é tarefa essencial e pré-requisito para a faina eficaz naquela área. ${ }^{26}$

Cumpre assinalar por fim e nessa dimensão que, ao longo do tempo, os originais da documentação "avulsa" das séries arquivísticas do AHU, ao serem consultados pelos pesquisadores, foram parcialmente alterados quanto à sua configuração primitiva. Equivale dizer: incontáveis dossiês foram sistematicamente destrinçados pelo manuseio nem sempre criterioso de seus guardiões e dos usuários. Por isso, as entradas/verbetes dos catálogos não correspondem necessariamente ao formato do documento no ato de sua produção. Oxalá que, no futuro, com o emprego de recursos tecnológicos, a reconstituição ao status quo ante seja alcançada.

\section{CONSIDERAÇÕES FINAIS}

Desde 2014, as atividades da Coluso arrefeceram em ambos os países dela signatários e formadores. No Brasil, hoje, a Fundação Biblioteca Nacional é a instituição depositária oficial da produção científica do Projeto Resgate "Barão do Rio Branco". Nesse sentido, em 2017, a Presidência do órgão criou uma Coordenação de Cooperação e Difusão que, em parceria com a Unesco, vem se empenhando em repensar o Projeto Resgate com base na definição de 
estratégias e parâmetros metodológicos mais consistentes para a continuidade de suas atividades.

Assim é que, nos dias 25 e 26 de abril de 2018, como referido, a Biblioteca Nacional do Brasil promoveu, em suas instalações, o Seminário Internacional "Rumos do Resgate: signos globais da memória cultural brasileira”. Na oportunidade, dentre outros temas, analisou-se: a temporalidade abrangida pelo projeto; critérios de percepção, descrição e informação dos documentos; a identificação de fundos documentais relativos ao Brasil, inéditos ou pouco consultados, existentes em outros países; a disponibilização on-line dos documentos e a criação de estímulos para a produção científica e historiográfica a partir dos resultados do Projeto.

Razão pela qual, e pelas anotações que se acaba de fazer, cumpre à comunidade dos historiadores - e não só - participar de forma vigorosa para o êxito dos anunciados propósitos. Não seria o caso de, com base nas recomendações do texto da Anpuh, os historiadores, para além de propugnar pela continuidade do Projeto Resgate, estarem mais envolvidos nas suas futuras ações?

\section{REFERÊNCIAS}

ARCHIVIO Segreto Vaticano: Documentação referente ao Brasil. Recife: Fundação Joaquim Nabuco; Massangana, 2002.

ASSOCIAÇÃO NACIONAL DE HISTÓRIA (ANPUH). O perfil profissional dos historiadores atuantes em arquivos: documento final do Encontro. São Paulo, dez. 2012. Disponível em: http://apalopez.info/bieau/ANPUH-historiadores_em_arquivos.pdf; acesso em: 2 jan. 2018.

BARROS, Edval de S. "Negócios de tanta importância": o Conselho Ultramarino e a disputa pela condução da guerra no Atlântico e no Índico (1643-1661). Lisboa: Centro de História de Além-Mar; Faculdade de Ciências Sociais e Humanas / Universidade Nova de Lisboa; [Ponta Delgada]: Universidade dos Açores, 2008.

BEATO, Isabel. Catálogo da documentação avulsa existente no Arquivo Histórico da Marinha portuguesa com interesse para o Brasil e sua Marinha até 1825. Lisboa: Arquivo Histórico da Marinha, 2000a. (ex. policopiado).

Catálogo da documentação encadernada existente no Arquivo Histórico da Marinha portuguesa com interesse para o Brasil e sua Marinha até 1825. Lisboa: Arquivo Histórico da Marinha, 2000b. (ex. policopiado).

BELlOTTO, Heloísa L. Arquivística: objetos, princípios e rumos. São Paulo: Associação de Arquivistas de São Paulo, 2002. Arquivo: estudos e reflexões. Belo Horizonte: Ed. UFMG, 2014. 
BELlOTTO, Heloísa L.; DIAS, Érika Simone de A. C. (Org.) Catálogo dos documentos manuscritos avulsos existentes no Arquivo Histórico Ultramarino de Lisboa / IICT / Portugal (1581-1834) referentes a ultramar, serviço de partes, visita do ouro, contratos do sal, Brasil-Geral. Rio de Janeiro: Ministério da Cultura, 2011.

BOSCHI, Caio. Antecedentes do Projeto Resgate. In: ARQUIVO NACIONAL. Revisitando a história colonial brasileira: balanço das realizações de um programa de cooperação Brasil-Portugal na área de arquivos. Rio de Janeiro, 2001. p.6-11.

. O Brasil-Colônia nos arquivos históricos de Portugal: roteiro sumário. São Paulo: Alameda, 2010.

. Exercícios de pesquisa histórica. Belo Horizonte: Ed. PUC Minas, 2011.

Projeto Resgate: antecedentes e corolários. Cadernos de História, Belo Horizonte, v.8, n.9, p.11-25, 10 sem. 2006. Disponível em: http://periodicos.pucminas. br/index.php/cadernoshistoria/article/view/1731/1872; acesso em: 24 jan. 2017.

BOSCHI, Caio (Coord.) Inventário dos Manuscritos Avulsos Relativos a Minas Gerais existentes no Arquivo Histórico Ultramarino (Lisboa). Belo Horizonte: Fundação João Pinheiro; Centro de Estudos Históricos e Culturais, 1998. 3v.

CAETANO, Marcelo. Do Conselho Ultramarino ao Conselho do Império. Lisboa: Agência Geral das Colônias, 1943.

. O Conselho Ultramarino: esboço de sua história. Lisboa: Agência Geral do Ultramar, 1967.

. O Conselho Ultramarino: esboço de sua história: Rio de Janeiro: Sá Cavalcante Ed., 1969.

CATÁlOGO dos Documentos Mandados Copiar pelo Sr. D. Pedro II. Revista do Instituto Histórico e Geográfico Brasileiro, Rio de Janeiro, v.109, t.67, pt. 1, 1904.

COMISSÃO LUSO-BRASILEIRA PARA SALVAGUARDA E DIVULGAÇÃO DO PATRIMÔNIO DOCUMENTAL (COLUSO): Seção Brasileira. Relatório de atividades 2010-2014. Rio de Janeiro: Serviço de Documentação da Marinha, 2014. Disponível em: http://www.conarq.arquivonacional.gov.br/images/coluso/publicacoes/Relatorio_Coluso_2010-2014.pdf; acesso em: 15 jan. 2018.

CRUZ, Miguel Dantas da. Um império de conflitos: o Conselho Ultramarino e a defesa do Brasil. Lisboa: ICS Imprensa de Ciências Sociais, 2015.

DICIONÁRIO Brasileiro de Terminologia Arquivística. Rio de Janeiro: Arquivo Nacional, 2005. (Publicações Técnicas, 51).

FARGE, Arlette. O sabor do arquivo. Trad. Fátima Murad. São Paulo: Edusp, 2009.

FARIA, Maria Dulce de. Catálogo da Coleção Cartográfica e Iconográfica Manuscrita do Arquivo Histórico Ultramarino. Rio de Janeiro: Museu de Astronomia e Ciências Afins, 2011. (Acompanha CD-ROM).

GREGÓRIO, David José F. Descrição arquivística: série "Lugares do Norte de África” do fundo "Conselho Ultramarino" do Arquivo Histórico Ultramarino. Relatório (Estágio de Mestrado em Ciências da Informação e da Documentação, Área de 
Especialização em Arquivística) - Universidade Nova de Lisboa, Faculdade de Ciências Sociais e Humanas. Lisboa, 2017.

A HISTÓRIA do Brasil no Arquivo do Instituto Histórico e Geográfico Brasileiro - séc. XVIII: documentos do Conselho Ultramarino. Revista do Instituto Histórico e Geográfico Brasileiro, Rio de Janeiro, v.259, p.218-364, abr./jun. 1963.

MARTINHEIRA, José Sintra. Catálogo dos códices do fundo do Conselho Ultramarino relativos ao Brasil existentes no Arquivo Histórico Ultramarino. Rio de Janeiro: Real Gabinete Português de Leitura; Lisboa: Fundação Calouste Gulbenkian, 2001.

MIRANDA, Tiago C. P. dos Reis. Antes do AHU: breve história custodial (ca. 18501931). s.d. Disponível em: http://www.cham.fcsh.unl.pt/files/file_000086.pdf; acesso em: 31 jan. 2018.

. O núcleo do 'Reino' do Arquivo Histórico Ultramarino: entre a história administrativa e a história custodial. Nova Cidadania, Lisboa, ano VIII, n.30, p.6062, out./nov. 2006.

MONTEIRO, Ana Rita A. Legislação e actos de posse do Conselho Ultramarino (16421830). Porto: Universidade Portucalense, 1997.

MONTEIRO, Nuno Gonçalo. A Secretaria de Estado dos Negócios do Reino e a administração de Antigo Regime (1736-1807). In: ALMEIDA, Pedro T. de; SOUSA, Paulo S. e (Coord.) Do Reino à Administração Interna: história de um ministério (1736-2012). Lisboa: Imprensa Nacional - Casa da Moeda, 2015. p.23-38.

MYRUP, Erik Lars. Governar à distância: o Brasil na composição do Conselho Ultramarino, 1642-1833. In: SCHWARTZ, Stuart; MYRUP, Erik Lars (Org.) O Brasil no império marítimo português. Trad. Fernanda T. Luciani e João P. Marão. Bauru, SP: Edusc, 2009. p.263-298.

To rule from Afar: The Overseas Council and the Making of the Brazilian West, 1643-1807. PhD Dissertation - Yale University. New Haven, Conn., 2006.

PORTUGAL. Instituto dos Arquivos Nacionais / Torre do Tombo. Direcção de Serviços de Arquivística - "Conselho Ultramarino". In: GUIA GERAL dos Fundos da Torre do Tombo: Instituições do Antigo Regime, Administração Central (2). Coord. Maria do Carmo Jasmins Dias Farinha; António Frazão; elab. António Frazão; fot. José António Silva. Lisboa: IAN/TT, 1999. v.2, p.143-146. (Instrumentos de Descrição Documental).

REIS, Gilson Sérgio M. (Coord.) Catálogo de documentos manuscritos avulsos da Secretaria do Conselho Ultramarino. Rio de Janeiro: Nórdica; Real Gabinete Português de Leitura; Lisboa: Fundação Calouste Gulbenkian, 2002.

RODRIGUES, José Honório. A pesquisa histórica no Brasil. 2.ed. São Paulo: Cia. Ed. Nacional, 1969. (Brasiliana, Grande Formato, 2).

ROSA, Maria de Lurdes. Apresentação. Arquivos de família: para um roteiro de temas e problemas. In: ROSA, Maria de Lurdes (Org.) Arquivos de família, séculos 
XIII-XX: que presente, que futuro? Lisboa: Instituto de Estudos Medievais (IEM); Centro de História de Além-Mar (CHAM), 2012.

WANDERLEY, Regina (Coord.) Homens, mares e terras: inventário analítico da documentação colonial portuguesa na África, Ásia e Oceania integrantes do acervo do Instituto Histórico e Geográfico Brasileiro. Rio de Janeiro: Instituto Histórico e Geográfico Brasileiro; Universidade do Estado do Rio de Janeiro; COLUSO, 2001. Homens, mares e terras: inventário analítico da documentação colonial portuguesa na África, Ásia e Oceania integrantes do acervo do Instituto Histórico e Geográfico Brasileiro. Revista IHGB, Rio de Janeiro, v.166, n.427, p.27-570, abr./ jun. 2005.

\section{NOTAS}

${ }^{1}$ Professor do Departamento de História da PUC Minas, professor aposentado do Departamento de História da UFMG. O autor agradece a Maria Eduarda Marques, Kátia Jane S. Machado, Lúcia Ricotta Vilela Pinto, Ana Canas Martins, José Sintra Martinheira e Renato Venancio informações atualizadas sobre as atividades do Projeto Resgate e sobre os instrumentos de acesso ao fundo do arquivo do Conselho Ultramarino.

${ }^{2}$ Sobre a trajetória e os resultados das incursões em arquivos e bibliotecas realizadas por brasileiros ao longo dos séculos XIX e XX em instituições estrangeiras detentoras de documentação respeitante à América portuguesa, consulte-se: RODRIGUES, 1969. Para o caso específico, veja-se: BOSCHI, 2010.

${ }^{3}$ A documentação reproduzida nas mencionadas missões foi depositada no Arquivo do Instituto Histórico e Geográfico Brasileiro (IHGB) e encontra-se disponível para consulta in loco. Grosso modo, são 73 volumes manuscritos compondo a Coleção "Arquivo do Conselho Ultramarino". Para conhecimento mais detalhado, consulte-se: a) CATÁLOGO..., 1904; b) A HISTÓRIA..., 1963. Ressalve-se que se trata de catálogos incompletos, tornando indispensável o contato direto com a documentação. Fração importante desse acervo teve divulgação específica, como em WANDERLEY, 2001 (também publicado em WANDERLEY, 2005).

${ }^{4}$ Doravante referenciada simplesmente pela sigla Coluso.

${ }^{5}$ A organização dos documentos avulsos sobre Minas Gerais depositados no Arquivo Histórico Ultramarino resultou de projeto coordenado por Caio Boschi, com financiamento do Conselho Nacional de Desenvolvimento Científico e Tecnológico (CNPq), na órbita da Comissão de Eventos Históricos (criada em 1986), da Diretoria das áreas de Ciências Humanas (1987) e de Ciências Humanas e Sociais Aplicadas (1988-1989). Contou com o apoio da Pontifícia Universidade Católica de Minas Gerais (PUC Minas) e da então Associação Nacional dos Professores Universitários de História (Anpuh). Cf. BOSCHI, 1998.

${ }^{6} \mathrm{O}$ Projeto Resgate foi instituído e fundamentou seus princípios na Resolução ${ }^{\circ}$ 
4212/1974 da Unesco, a qual, na sequência, criou e implementou o Projeto Guia de Fontes para a História das Nações. Cf. COLUSO, 2014, p.85.

${ }^{7}$ A Série Brasil integra um dos três fundos preservados no AHU, correspondendo à documentação do período denominado de Antigo Regime, abrangendo fontes históricas datadas do século XVI até a terceira década do XIX, segundo critérios adotados pela instituição para organizar o acervo.

${ }^{8}$ Compõe-se de 759 códices, com mais de 150 mil páginas de registros manuscritos (cf. MARTINHEIRA, 2001). O fundo do arquivo do Conselho Ultramarino reúne documentação de várias instituições da administração central portuguesa que superintenderam os negócios ultramarinos, principalmente o Conselho Ultramarino e a Secretaria de Estado da Marinha e Ultramar, e também contém documentos avulsos e códices desde o século XVI até 1833. Insista-se em afirmar que esse fundo está digitalizado e disponível à consulta em: bndigital.bn.gov.br/dossies/projeto-resgate-barao-do-rio-branco. O título desse catálogo não invalida que, sob a égide do Conselho Ultramarino, estejam também nele compilados códices provenientes de cartórios do Conselho da Fazenda, órgão que antecedeu o Ultramarino, e, sobretudo, códices procedentes da Secretaria de Estado da Marinha e Ultramar, e ainda "livros cuja proveniência é tão diversa quanto às repartições públicas existentes nas capitanias e comarcas do Brasil Colônia, e nalguns casos incerta quanto ao órgão produtor e receptor" (op. cit., p.29). Uma listagem dos códices de interesse específico para a História do Brasil pode ser lida em: BOSCHI, 2010, p.87-88 e 90-93.

${ }^{9}$ Cf. REIS, 2002. Trata-se de 2.020 peças documentais não encadernadas, dispostas em 22 caixas metálicas, compreendendo documentos de todo o período de existência do órgão, isto é, de 1642 a 1833. O catálogo está disponível em: http://actd.iict.pt/eserv/actd:CUc089/ CU-ConselhoUltramarino.pdf. Os documentos, na íntegra, estão digitalizados em: https:// bndigital.bn.gov.br/dossies/projeto-resgate-barao-do-rio-branco/.

${ }^{10} \mathrm{Cf}$. FARIA, 2011. Esse instrumento elenca 700 imagens, detalhadamente identificadas em 435 entradas/verbetes. Na realidade, considerável - se não a maior - quantidade dessas peças manuscritas, originalmente, integravam, isto é, eram anexos de documentos político-administrativos enviados por autoridades coloniais para órgãos da administração central em Lisboa.

${ }^{11}$ BELLOTTO; DIAS, 2011. Destaque-se que estes conjuntos documentais estão igualmente disponíveis para consulta on-line: http://resgate.bn.br/docreader/docmulti.aspx?bib=resgate.

${ }^{12}$ Para melhor conhecimento, reporte-se a: http://actd.iict.pt/view/actd:CUc076\#. Sobre a série e suas vicissitudes, leia-se: MIRANDA, 2006.

${ }^{13}$ Importante destacar que o Projeto Acervo Digital Angola Brasil (Padab), desenvolvido em 2006 sob a coordenação da pesquisadora brasileira Marisa de Carvalho Soares, digitalizou e permutou 108 códices do Arquivo Nacional de Angola com a coleção de documentos relativos à África existentes no Arquivo do Instituto Histórico e Geográfico Brasileiro (IHGB). Cf. Nota 3 acima. 
${ }^{14}$ Em contrapartida e complementarmente, a totalidade da documentação em livros e em códices está registrada em: http://actd.iict.pt/eserv/actd:CUF006a001/AHU-CatalogoGeralCodices.pdf.

${ }^{15}$ Para detalhamento e ampliação destas informações, reporte-se a: COLUSO, 2014, p.9293.

${ }^{16}$ Esse é o primeiro de cinco volumes até agora publicados, em edições bilíngues, sob a coordenação da referida professora da Universidade de Leiden, compondo a denominada Série Mauritiana. Dessa massa documental, a que se encontra sob a guarda do Arquivo Nacional, em Haia, está digitalizada, parte da qual com os correspondentes verbetes. Cf.: www.gahetna.nl e/ou http://www.gahetna.nl/collectie/archief/ead/gahetnascans/zoekterm/Brasil/eadid/1.05.01.01/wollig/uit/volledige-tekst/aan/gebruikersinbreng/aan.

${ }^{17}$ A inventariação no Arquivo Secreto Vaticano foi concluída. O instrumento de busca está graficamente preparado, mas não impresso. Cf. ARCHIVIO..., 2002. A Biblioteca Nacional do Brasil anuncia, para breve, a disponibilização das imagens no seu site do Projeto Resgate / bndigital.

${ }^{18}$ Para clareza, explicite-se que, em ambos os casos, o vocábulo arquivo significa "conjunto de documentos produzidos e acumulados por uma entidade coletiva, pública ou privada, pessoa ou família, no desempenho de suas atividades, independentemente da natureza do suporte" (DICIONÁRIO..., 2005, p.27).

${ }^{19}$ Deixa-se de analisar aqui as razões da emergência da Secretaria de Estado dos Negócios da Marinha e Domínios Ultramarinos e as competências e atribuições que esse órgão tinha vis-à-vis ao Conselho Ultramarino na esfera da administração central no Antigo Regime português, bem como os conflitos de jurisdição entre eles. Assinale-se, todavia, que essa alteração político-administrativa fez aumentar consideravelmente a produção documental, tanto aquela exarada no Reino como a emitida na Colônia, sobretudo na segunda metade do século.

${ }^{20}$ Sobre essas sucessivas mudanças espaciais e institucionais e a consequente desordem nos conjuntos documentais, leia-se: MIRANDA, s.d.

${ }^{21}$ CAETANO, 1943. O texto desse livro foi ampliado e republicado em CAETANO, 1967. Há versão brasileira: CAETANO, 1969.

${ }^{22}$ Myrup é autor da produção acadêmica de maior fôlego sobre a instituição em causa, mas cuja essência se atém a estudos voltados para outras temáticas (MYRUP, 2006). O mesmo ocorre com BARROS, 2008; com CRUZ, 2015, e também com MONTEIRO, 1997.

${ }^{23}$ Cf. MONTEIRO, 2015.

${ }^{24}$ São dez livros de registros do Conselho Ultramarino no ANTT. Para informação sobre o conteúdo, recorra-se a: PORTUGAL, 1999. O acesso à integra dos livros pode ser feito em: http://digitarq.arquivos.pt/details?id=4167269.

${ }^{25}$ Sobre o Brasil, não há núcleo especial, diluindo-se a documentação por todo o acervo. Esse arquivo histórico pode ser consultado a partir de índices informatizados existentes na 
sua Sala de Leitura, cabendo sobressair os volumes de números 30, 31, 32, 33, 34, 35, 36, 38, 39 e 43. O índice n 30 (vol. 1 dos Códices) abarca códices devolvidos pelo Arquivo Histórico Ultramarino, de documentos provenientes do Comando Geral da Armada e da Direção-Geral da Marinha. Para conhecimento mais circunstanciado sobre a documentação relativa ao Brasil, veja-se: BEATO, 2000b. Utilizando-se do referido índice, a autora faz referência a 208 livros-códices. O trabalho é complementado por índices antroponímico, toponímico, de assuntos e de imagens; da mesma autora, cite-se: BEATO, 2000a. Há referência a 319 documentos. A obra é identicamente finalizada por índices antroponímico, toponímico, de assuntos e de imagens.

${ }^{26}$ No Seminário Internacional "Rumos do Resgate: signos globais da memória cultural brasileira", recentemente realizado na cidade do Rio de Janeiro, o historiador português Tiago Miranda divulgou a sua "descoberta", nos acervos do Arquivo Histórico Ultramarino, de originais de 10 de 11 "Índices dos Armários" (sic), com data anterior a 1808, que podem permitir a reconstituição da estrutura administrativa dos conjuntos documentais do Conselho Ultramarino.

Artigo recebido em 16 de fevereiro de 2018.

Aprovado em 28 de abril de 2018.

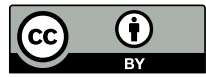

